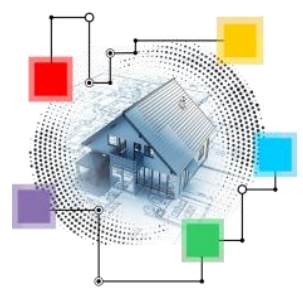

\author{
XIII SIMPÓSIO NACIONAL DE SISTEMAS PREDIAIS \\ DESEMPENHO E INOVAÇÃO \\ DE SISTEMAS PREDIAIS HIDRÁULICOS \\ SÃO PAULO - 04 DE OUTURO DE 2019
}

\title{
Conservação de água em sistemas prediais hidráulicos: estudo de caso em uma residência
}

\section{Water conservation in building water systems: case study in residence}

\author{
COSTA, Ursula'; CAMPOS, Marcos2; SILVEIRA FILHO, Agnelo 3; MARTINS, Marcia 4 \\ ${ }^{1}$ UNIFEI, Av. BPS, 1303 - Itajubá, MG, ursulawilberg@ gmail.com \\ ${ }^{2}$ UNIFEI, marcos.campos3187@gmail.com \\ ${ }^{3}$ UNIFEI, agnelolimasilveira@gmail.com \\ ${ }^{4}$ UNIFEI, marciavlmartins@gmail.com
}

\begin{abstract}
RESUMO
Os desperdícios de água doce tratada no Brasil vêm se destacando, principalmente pelos altos índice de perdas, baixa eficiência de equipamentos, e pela utilização de água potável para usos não nobres no dia-adia. Sendo assim, o aproveitamento da água de chuva para fins não potáveis apresenta-se como uma ferramenta para minimizar o uso deste bem. Deste modo, este trabalho tem como objetivo a análise técnica e econômica de um sistema de aproveitamento de água de chuva para uma residência. O dimensionamento deste foi realizado de acordo com a norma NBR 15.527 (ABNT, 2007). O reservatório foi dimensionado utilizando do método de Rippl. Conclui-se que o sistema de aproveitamento de água de chuva é viável técnica e economicamente, pois resultou numa redução de $18,3 \%$ no consumo médio mensal de água potável e um tempo de retorno do investimento de 7,4 anos.
\end{abstract}

Palavras-chave: Reúso de água, Consumo eficiente, Aproveitamento de água de chuva.

\begin{abstract}
Waste of treated freshwater in Brazil has been highlighted, mainly due to high losses, low efficiency of equipment, and the use of drinking water for non-noble uses in everyday life. Therefore, the use of rainwater for non-potable purposes becomes a tool to minimize the use of this resource. Thus, this work has as objective the technical and economic analysis of a rainwater reuse system for a residence. The sizing of this will be carried out according to the Brazilian Standard NBR 15.527 (ABNT, 2007). The reservoir was scaled using the Rippl method. It is concluded that the rainwater harvesting system is technically and economically viable, as it resulted in an $18.3 \%$ reduction in the average monthly drinking water consumption and a paybck of 7.4 years.
\end{abstract}

Keywords: Water reuse, Efficient consumption, Rainwater harvesting. 


\section{INTRODUÇÃO}

Segundo Luz (2005 apud Pinheiro e Araújo, 2016), o uso racional dos recursos hídricos com a reciclagem da água, a eliminação de desperdícios, o reúso de águas servidas e o aproveitamento das águas de chuva, representam uma economia de recursos que favorece a proteção do recurso natural. Portanto, a conservação de água em residências contribui para diminuir as perdas e estimular o uso não potável deste bem. Sistemas de aproveitamento da água de chuva e instalação de equipamentos hidrossanitários eficientes se tornam ferramentas importantes para minimizar o consumo de água.

Este trabalho tem como objetivo a análise técnica e econômica de um sistema de aproveitamento de água de chuva para uma residência localizada no município de São Lourenço, Minas Gerais.

\section{REVISÃO BIBLIOGRÁFICA}

Conforme Santos et al. (2005), nos últimos anos tem havido uma conscientização sobre o fato de que a água é um recurso finito e de que sua disponibilidade, no que diz respeito a quantidade e qualidade, está sujeita às condições do meio antrópico.

De fato, o uso indevido da água de abastecimento tem seu aspecto cultural, especialmente em locais com grande oferta hídrica. O Brasil se encontra em uma situação privilegiada quando comparado a outros países, uma vez que possui uma disponibilidade hídrica per capita considerada muito satisfatória (ANA, 2018). Acontece que a distribuição espacial deste recurso não é igualitária, resultando na falta de água em algumas regiões, como grande parte do Nordeste, e excedente da mesma, como na região Amazônica. Nas regiões mais urbanizadas a escassez hídrica é devido à elevada densidade populacional e a poluição dos corpos de água.

Uma análise interessante é que, de acordo com Dias et al. (2018), pode-se perceber, através de estudos, que o aumento de tarifas de água causa redução significativa no consumo residencial deste recurso.

Santos et al. (2005) defende que as possíveis ações de conservação de água vão da utilização alternativa de água, como o aproveitamento de águas de chuva e de águas cinzas, até o uso racional da água, que inclui o uso de dispositivos economizadores, medição individualizada e a conscientização dos usuários.

Oliveira (1999) divide as ações de conservação em três níveis, que são: o nível macro (pertinentes à grandes sistemas ambientais e bacias hidrográficas), nível meso (pertinentes aos sistemas públicos de abastecimento de água e coleta de esgoto) e as de nível micro (pertinentes às edificações). Em todos os níveis são múltiplas as oportunidades de detecção de melhorias e ação. 
De acordo com Campisano e Modica (2012), o reúso de água para usos potáveis e não potáveis tem sido visto como uma importante fonte de água, especialmente em áreas urbanas, sendo esta uma solução comumente vista em regiões com escassez de água.

Os autores Oliveira et al. (2007) destacam que muitas vezes a água potável é utilizada em todas as atividades do empreendimento ou recinto, sem se realizar estudo do uso pretendido. Por isto, ainda de acordo com os autores, o conceito de conservação de água vai além do estudo da demanda, mas também da oferta desse recurso, de uma forma que usos mais nobres possam ser supridos por águas de qualidade inferior, sempre que possível.

Neste contexto, a necessidade de um Plano de Conservação de Água - PCA é avistada. Nele, são pensadas ações tanto de gestão da demanda como de gestão da oferta, para que possam ser aplicadas em diferentes edificações. Na Erro! Fonte de referência não encontrada. é apresentado um esquema macro de uma edificação com PCA.

FIGURA 1- Esquema macro de uma edificação com PCA.

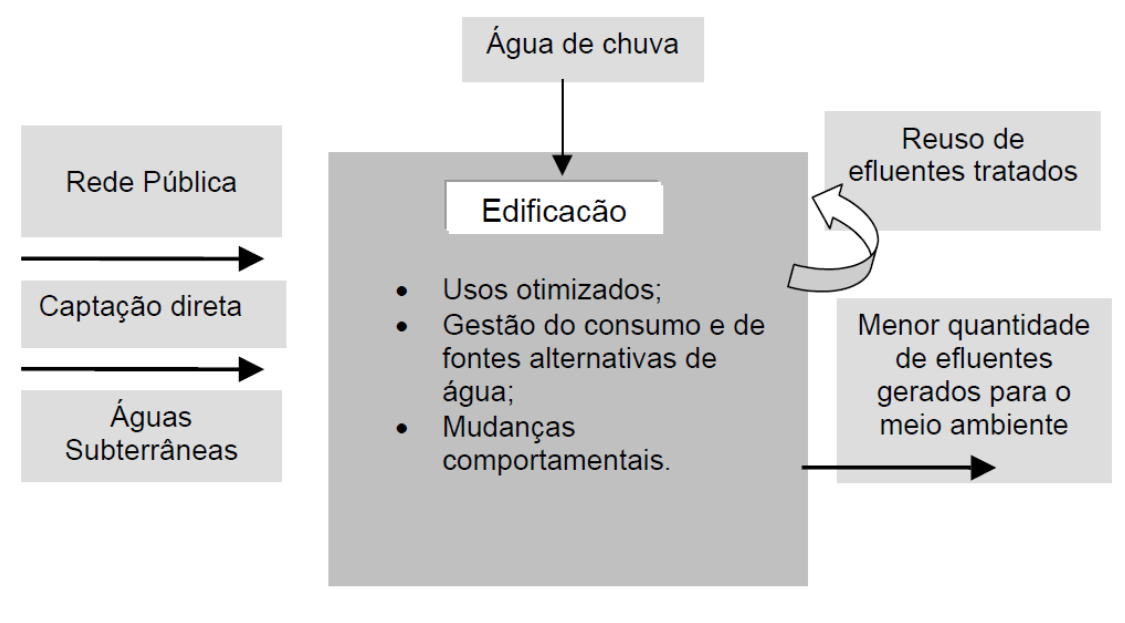

Fonte: BRASIL, 2003.

\section{METODOLOGIA}

O presente trabalho constitui-se na aplicação da metodologia do Programa de Conservação da Água apresentada no Documento Técnico de Apoio nº F3 (BRASIL, 2003) em uma residência familiar, tendo como foco a implantação de um sistema de aproveitamento de água de chuva.

Serão consideradas as seguintes etapas: auditoria inicial, avaliação da demanda da água, avaliação da oferta da água, estudo de viabilidade técnica e econômica, escolha do cenário ótimo e gestão do uso da água.

\subsection{Auditoria inicial}

A auditoria inicial tem como objetivo a coleta de informações necessárias para a avaliação dos fluxos da água na edificação, quantidade e qualidade assim como a forma de utilização, e subdivide-se em: análise documental, análise da edificação e setorização para o 
monitoramento do consumo.

A análise documental tem como objetivo o levantamento de informações relevantes para o entendimento da edificação sobre o ponto de vista de água, tais como projetos arquitetônicos e hidráulicos, conta de água, procedimentos existentes etc.

Com os dados obtidos será realizada uma primeira análise a fim de determinar os indicadores de consumo apropriados.

Será realizada uma vistoria com o objetivo de obter um levantamento que permita complementar a análise documental e concluir a auditoria inicial, promovendo assim um mapeamento qualitativo e quantitativo do uso da água na residência. Serão avaliados os seguintes aspectos: procedimentos de utilização da água, condições dos sistemas hidráulicos, perdas físicas, usos inadequados e usuários envolvidos.

\subsection{Avaliação da demanda da água}

Será realizada inicialmente uma setorização do consumo de água para o monitoramento do consumo de acordo com o padrão de qualidade exigido.

Visto que se trata de um ambiente residencial, a setorização será estruturada da seguinte forma: uso potável (água destinada ao preparo de alimentos, banho e higiene pessoal) e uso não potável (água destinada à limpeza da área externa, sanitários e irrigação da horta).

Será realizada a medição de vazão e cronometragem do tempo de uso diário de cada torneira da residência, assim como a quantidade de água utilizada por ciclo e número de ciclos diários nos sanitários e máquina de lavar, obtendo assim o consumo de água diário em cada componente.

Será realizada a comparação das medições com os dados obtidos na auditoria inicial determinando o padrão de consumo de água na residência, assim como as intervenções necessárias para que haja eficiência hídrica no consumo e redução de perdas físicas nas instalações.

\subsection{Avaliação da oferta da água de chuva}

Neste estudo será considerada como fonte alternativa a água pluvial coletada no telhado da residência. $\mathrm{O}$ dimensionamento do sistema de aproveitamento da água pluvial será realizado de acordo com a norma NBR 15.527 (ABNT, 2007).

\section{RESULTADOS}

\subsection{Avaliação da oferta de água da chuva}

Para avaliar o potencial de aproveitamento de água de chuva foi utilizada a série histórica entre 01/1961 e 12/1998 da estação pluviométrica 0224517, operada pela Agência Nacional de Águas - ANA (S $22^{\circ}$ 6' 0,00”; W 45 1' 0,12”). Os dados são dados brutos de nível de consistência 1, e a estação apresenta algumas lacunas, principalmente entre os anos de 1971 e 1974. Na FIGURA 2 está apresentada a média mensal pluviométrica. 
FIGURA 2: Média mensal - Estação 02245107

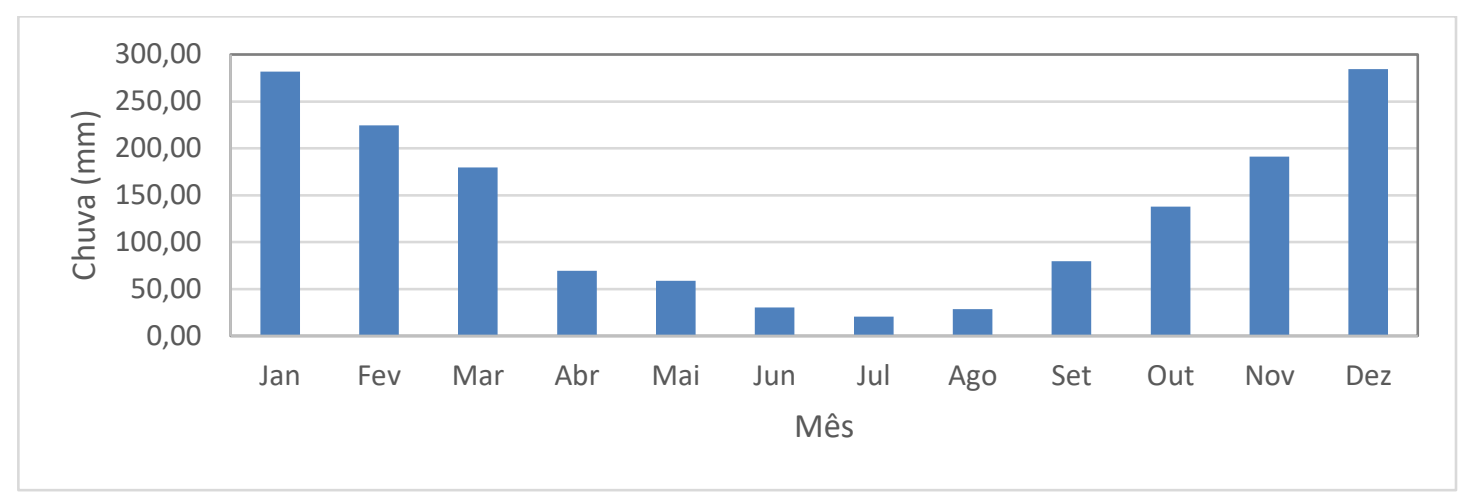

Fonte: autoria própria

\subsection{Levantamento da demanda mensal de água}

A residência em estudo apresenta um consumo médio de $26 \mathrm{~m}^{3}$ por mês, conforme extrato de leitura do Serviço Autônomo de Água e Esgoto - SAAE.

Dividindo o consumo da residência em estudo em 3 partes, pode-se separar a demanda de água possível de aproveitamento.

i. Consumo interno: torneiras, banho, limpeza de áreas internas e cozinha;

ii. Consumo para limpeza externa: lavagem do quintal, frente da casa etc.;

iii. Consumo para irrigação: irrigação das mudas e jardim.

Os consumos para limpeza externa e para irrigação do jardim e mudas serão os beneficiados pelo aproveitamento da água da chuva.

\subsection{Consumo destinado a limpeza externa}

Para consumo de água destinada a limpeza da área externa, Equação (1), foram consideradas quatro limpezas mensais no quintal e uma limpeza mensal na área do pomar, com duração de respectivamente 0,5 horas e 0,9 horas. Ambas as limpezas foram realizadas através de uma lavadora de pressão com vazão de $460 \mathrm{~L} / \mathrm{h}$.

$C_{1}=\left[\left(V \cdot T_{1} \cdot N_{1} / 1000\right)\right]+\left[\left(V \cdot T_{2}+N_{2}\right) / 1000\right]$

sendo:

$\mathrm{Cl}$, o consumo mensal de água destinada a lavagem externa $\left(\mathrm{m}^{3} / \mathrm{mês}\right)$;

$\mathrm{V}$, a vazão da lavadora de pressão $(\mathrm{L} / \mathrm{h})$;

$\mathrm{N}_{1}$, o número de lavagens mensais do quintal;

$\mathrm{N}_{2}$, o número de lavagens mensais do pomar;

$\mathrm{T}_{1}$, o tempo de lavagem do quintal (h);

$\mathrm{T}_{2}$, o tempo de lavagem do pomar (h).

O consumo mensal de água destinada a limpeza da externa resultou em $1,33 \mathrm{~m}^{3} / \mathrm{mês}^{\mathrm{e}}$ representa cerca de 5\% do consumo médio mensal. 


\subsection{Consumo para irrigação}

A irrigação do pomar e jardim foi considerada necessária nos dias de precipitação menor do que $15 \mathrm{~mm}$. Assim, a partir da série histórica pluviométrica extraiu-se a quantidade de dias no mês que exigem irrigação. O consumo médio diário de água para irrigação, 381,75 L, foi estimado a partir do consumo médio diário de cada planta multiplicado pelo número de plantas. O consumo médio mensal de água para irrigação foi obtido através da Equação 2.

$C_{i}=n \cdot i / 1000$

sendo:

$\mathrm{C}_{\mathrm{i}}$, o consumo médio mensal de água destinada a irrigação ( $\left.\mathrm{m}^{3} / \mathrm{mês}\right)$;

$\mathrm{n}$, o número de dias com precipitação menor que $15 \mathrm{~mm}$;

i, o somatório do consumo médio diário de água das plantas (L/dia).

O consumo médio mensal de água para irrigação resultou em $10,46 \mathrm{~m}^{3}$ que representa $40,4 \%$ do consumo total da residência.

\subsection{Dimensionamento do sistema de reservação - Método Rippl}

Para o cálculo do reservatório de água de chuva através do método de Rippl foi considerada a demanda média mensal para limpeza de área externa e irrigação do pomar e jardim de $4,75 \mathrm{~m}^{3}$, que representa $40 \%$ da demanda de água não potável, $11,79 \mathrm{~m}^{3}$, a área de captação da residência igual a 93,13 $\mathrm{m}^{2}$ e a precipitação média mensal da estação 02245107 (Figura 2). O volume do reservatório resultou em $7,5 \mathrm{~m}^{3}$.

Na Figura 3 é apresentada a localização do reservatório.

FIGURA 3 - Concepção do Sistema de Aproveitamento da Água da Chuva - Corte.

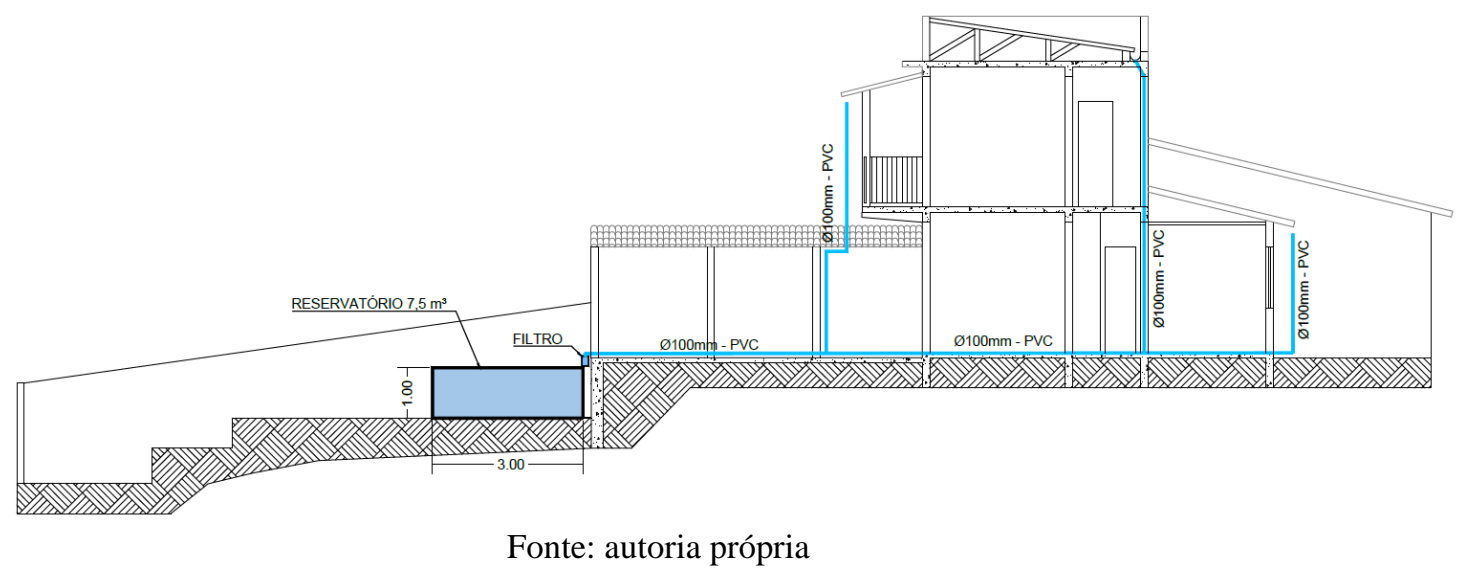

\subsection{Análise econômica}

$\mathrm{O}$ custo do sistema de aproveitamento de água de chuva foi estimado em $\mathrm{R} \$ 4.804,33$ (reservatório de concreto armado, tubulações de $100 \mathrm{~mm}$, filtro de folhas, reservatório de descarte, bomba e acessórios). Foi obtida uma redução do consumo médio mensal de água 
potável de $18,3 \%$ que resultou na economia média mensal na conta de conta de água de $\mathrm{R} \$ 54,23$. O tempo de retorno do investimento foi estimado em 7,4 anos.

\section{CONCLUSÃO}

Ciente da finitude do recurso água, foi analisada técnica e economicamente a implantação de um sistema de aproveitamento de chuva em residência unifamiliar para limpeza da área externa e irrigação de pomar e jardim.

Foi estimada uma redução no consumo médio mensal de água potável de $18,3 \%$. O tempo de retorno do investimento mostrou-se elevado, 7,4 anos. Uma alternativa para reduzir os custos de implantação seria a substituição do reservatório em concreto armado por reservatório polietileno.

Em uma abordagem ambiental e social, a redução do consumo residencial está relacionada com a preservação ambiental e a conscientização deste recurso finito, e por isto, sua aceitação é um desafio com grandes retornos para a sociedade como um todo.

\section{REFERÊNCIAS}

AGÊNCIA NACIONAL DAS ÁGUAS (BRASIL) Conjuntura dos recursos hídricos no Brasil 2018: informe anual / Agência Nacional de Águas - Brasília: ANA, 2018

BRASIL. Ministério das Cidades. DTA - Documento Técnico de Apoio no F3. Código de prática de projeto e execução de sistemas prediais de água - conservação de água em edifícios (versão preliminar). Programa Nacional de Combate ao Desperdício de Água. Setembro, 2003. 68 p.

CAMPISANO, A., \& MODICA, C. (2012). Optimal sizing of storage tanks for domestic Rainwater harvesting in Sicily. Resources, Conservation, and Recycling, 63, 9-16.

DIAS, T. F., KALBUSCH, A., HENNING, E. Factors influencing water consumption in buildings in southern Brazil. Journal of Cleaner Production, 184 (2018) 160-167.

HOUSE-PETERS, L., PRATT, B., CHANG, H., 2010. Effects of urban spatial structure, sociodemographics, and climate on residential water consumption in Hillsboro, Oregon. J. Am. Water Resour. Assoc., 46 (3), 461-472.

HUSSIEN, W. A., MEMON, F.A., SAVIC, D.A., 2016. Assessing and modelling the influence of household characteristics on per capita water consumption. Water Resour. Manag. Int. J. Publ. Eur. Water Resour. Assoc. (EWRA) 30 (9), 2931e2955.

OLIVEIRA, G., MARCATO, F. S., SCAZUFCA, P., PIRES, R. C. Perdas de água 2018 (SNIS 2016): Desafios para disponibilidade hídrica e avanço da eficiência do saneamento básico. Trata Brasil Saneamento é Saúde. São Paulo, maio de 2018.

OLIVEIRA, L. H. Metodologia para a implantação de programa de uso racional da água em edifício. 1999. 344f. Tese (Doutorado em Engenharia Civil) Escola Politécnica, Universidade de São Paulo, São Paulo, 1999. 
OLIVEIRA, L. H., ILHA, M. S. O., Gonçalves, O., Ywashima, L., Reis, R. P. A. Levantamento de estado da arte: Água. Projeto Tecnologias para construção habitacional mais Sustentável. Finep. São Paulo. 2007.

PINHEIRO, L. G., ARAÚJO, A. L. C. Qualidade e aproveitamento da água de chuva. HOLOS, v. 8, p. 135-146, dez 2016.

SAAE. Serviço Autônomo de Água e Esgoto. Fatura Ligação 12507-0. Maio, 2019

SANTOS, D. C., LOBATO, M. B., VOLPI, N. M. P, BORGES, L. Z. Hierarquização de medidas de conservação de água em edificações residenciais com o auxílio da análise multicritério. Ambiente Construído, Porto Alegre, v. 6, n. 1, p. 31-47, jan./mar. 2006.

SILVA, L. C. C. da, FILHO, D. O., SILVA, I. R., PINTO, A. C. V., VAZ, P. N. Water sustainability potential in a university building - Case study. Sustainable Cities and Society, v. 47, 101489, mai. 2019.

SOBRINHO, R. A., BORJA, P. C. Gestão das perdas de água e energia em sistema de abastecimento de água da Embasa: um estudo dos fatores intervenientes na RMS. Engenharia Sanitária e Ambiental, v. 21 n. 4, p. 783-795, dez. 2016.

WILSON, C., WENG, Q. Assessing surface water quality and its relation with urban land cover changes in the Lake Calumet area, Greater Chicago. Environmental Management, v. 45, p. 10961111, mai. 2010. 